\title{
Investigation of the aluminium plasma electrolytic oxidation process
}

\author{
$\underline{\text { G. Henrion, }},{ }^{1}$ F. Jaspard, ${ }^{2}$ T. Czerwiec ${ }^{1}$, T. Belmonte ${ }^{1}$, A. Viola ${ }^{3}$ \\ ${ }^{1}$ LSGS (UMR-CNRS 7570) - Nancy-Université - Ecole des Mines - 54042 Nancy cedex (France). \\ ${ }^{2}$ GIE Harmony, 12 rue de l'artisanat, 67120 Duppighein (France) \\ ${ }^{3}$ Messier-Bugatti, 5 rue A. de St Exupéry, 67129 Molsheim cedex (France)
}

\section{I - Introduction}

Plasma electrolytic oxidation (PEO) [1-4], has gained growing interest for the recent years in light-weight metal (Al, Ti, and $\mathrm{Mg}$ alloy) oxidation [5]. Compared with conventional anodising, PEO treatments are usually achieved by using high voltage, low frequency (around $50 \mathrm{~Hz}$ ) AC supply in dilute alkaline electrolytes [1]. The oxide layers obtained by PEO processing of aluminium alloys are thick, hard and well-adherent to the substrate. As a consequence, the surface properties obtained after PEO treatments are promising for industrial applications. The oxide layer achieved on aluminium alloys are typically subdivided in two sublayers [6,7]: a porous layer at the surface and a compact layer near the substrate. The latter contains crystallized alumina, responsible for the very good mechanical properties of the oxide layers. As a consequence, the surface properties obtained after PEO treatments are promising for industrial applications.

Despite the considerable industrial interest in this process, there is no clear understanding on the underlying discharge mechanisms. Discharges produced during a PEO treatment are not stationary and their evolution can be characterized by different time scales. Indeed, the discharge number, localisation and aspect (colour, brightness...) evolve over the complete PEO treatment. Different process steps are reported in the literature $[8,9]$. The early beginning of a treatment is similar to a conventional anodizing, leading to the formation of an insulating layer. The aluminium oxide layer grows and becomes more and more insulating and acts as a diffusion barrier for oxygen. As the applied voltage reaches the breakdown potential of the oxide film, sparks appear that flash randomly all over the aluminium surface, allowing thus the growing to pursue.

This talk reports on the investigation of PEO processing of aluminium alloys by using the CERATRONIC ${ }^{\circledR}$ pulsed bipolar current supply [10]. It is shown that particular conditions may be established which strongly reduce the arcing that usually cause detrimental defect in the oxide layer for long treatment time (typically greater than 40-50 min.). This results in a "softer" process which is pointed out by spectroscopic measurements and video imaging of the micro-discharges during the PEO process. As a consequence thick homogenous layers may be grown with no large discharge channels. From the presented results, the importance of the negative charge density relative to the positive one is evidenced thus pointing out the benefit of using a pulse bipolar current supply.

\section{II - Experiment}

The experimental arrangement was previously detailed $[11,12]$. Briefly speaking it consists of an electrolysis tank. The electrolytic solution consists of $\mathrm{KOH}$ and $\mathrm{Na}_{2} \mathrm{SiO}_{3}$ diluted in distilled water; the resulting electrolyte conductivity ranges from 2.3 to $2.5 \mathrm{mS} / \mathrm{cm}$. A cooling system maintains the electrolyte temperature below $30^{\circ} \mathrm{C}$ during the process. The rectangular samples $\left(100 * 90 * 6 \mathrm{~mm}^{3}\right)$ immersed in the electrolyte are made of 2214-T6 aluminium alloy. They are

§ gerard.henrion@mines.inpl-nancy.fr 
cleaned with acetone before each treatment to avoid poisoning of the electrolyte bath and to ensure a reproducible initial surface contamination for each sample.

Two stainless steel counterelectrodes face both sides of the sample which are treated simultaneously. A pulsed bipolar current generator (CERATRONIC ${ }^{\circledR}$ process [10]) delivers current to the substrate. Except otherwise

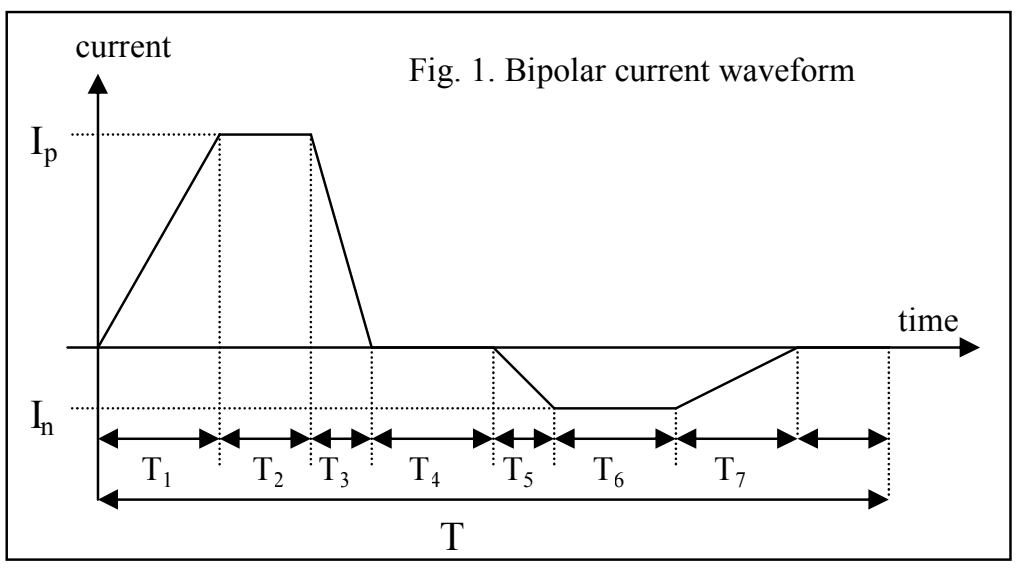
stated, the reported results have been acquired by using $\mathrm{I}_{\mathrm{p}}=76$ A corresponding to a positive current density of $38 \mathrm{~A} / \mathrm{dm}^{2}$. The current frequency is set at $100 \mathrm{~Hz}$. Process parameters, such as the period $(T)$, the different duration of each step in the current waveform $\left(T_{i}\right)$, the amplitude of the positive $\left(I_{p}\right)$ and negative $\left(I_{n}\right)$ current can be adjusted over a wide range. We define the parameter $\mathrm{R}$ as being the positive to negative charge quantity ratio (see figure 1 for the definition of $\left.\mathrm{T}_{\mathrm{i}}\right)$ :

$$
\mathrm{R}=\frac{\mathrm{q}_{\mathrm{p}}}{\mathrm{q}_{\mathrm{n}}} \quad \text { with } \quad \mathrm{q}_{\mathrm{p}}=\int_{0}^{\mathrm{T}_{1}+\mathrm{T}_{2}+\mathrm{T}_{3}} \cdot \mathrm{It} \quad \text { and } \quad \mathrm{q}_{\mathrm{n}}=\int_{\mathrm{T}_{1}+\mathrm{T}_{2}+\mathrm{T}_{3}}^{\mathrm{T}} \mathrm{I}_{\mathrm{n}} \cdot \mathrm{dt}
$$

In what follows, two different $\mathrm{R}$ values where used and the corresponding results compared: $\mathrm{R}=1.57$ and $\mathrm{R}=0.89$.

The micro-discharges occurring on the sample surface during the PEO process are characterized by means of optical emission spectroscopy (OES) with a spectral resolution of $0.3 \mathrm{~nm}$. The light emitted by the micro-discharges is collected by an optical fibre immersed in the electrolyte, and located a few centimetres from the sparks to optimise the collected light intensity and to reduce absorption by the electrolyte bath. The fast CCD camera imaging device (Kodak Motion Corder Analyzer, SR series) allows us to record video images of the micro-arcs with a time resolution of $2 \mathrm{~ms}$. The layer characteristics are investigated by use of scanning electron microscopy (SEM).

\section{III - Results and discussion}

\subsection{Sample processing with $R=1.57$}

As far as the PEO process goes on, strong variations in the microdischarges are observed as shown in fig. 2. When looking at the variation of the $\mathrm{Al}$ emission line $(\lambda=396.2 \mathrm{~nm})$, one distinguishes the different steps of a PEO process as described elsewhere [7, 8, 11-13]. At the very early beginning of the process, the huge increase in $\mathrm{Al}$ emission line intensity $\left(\mathrm{I}_{\mathrm{Al}}\right)$ is significant of a strong erosion of the sample surface due to the numerous sparks. At the end of this step, the alumina layer thickness is large enough to make the evaporation or sputtering of aluminium less effective. As a consequence, during that second step that lasts typically a few minutes, $\mathrm{I}_{\mathrm{Al}}$ decreases while the sparks progressively change to micro-arcs. Finally, the third step is characterized by a low and very noisy emission line of aluminium due to a thicker and thicker oxide layer. Meanwhile strong and bright arcs appear on the surface in place of micro-arcs which may cause detrimental defect in the growing layer.

SEM micrograph of the oxide layer grown during 140 minutes is presented in figure 3. 

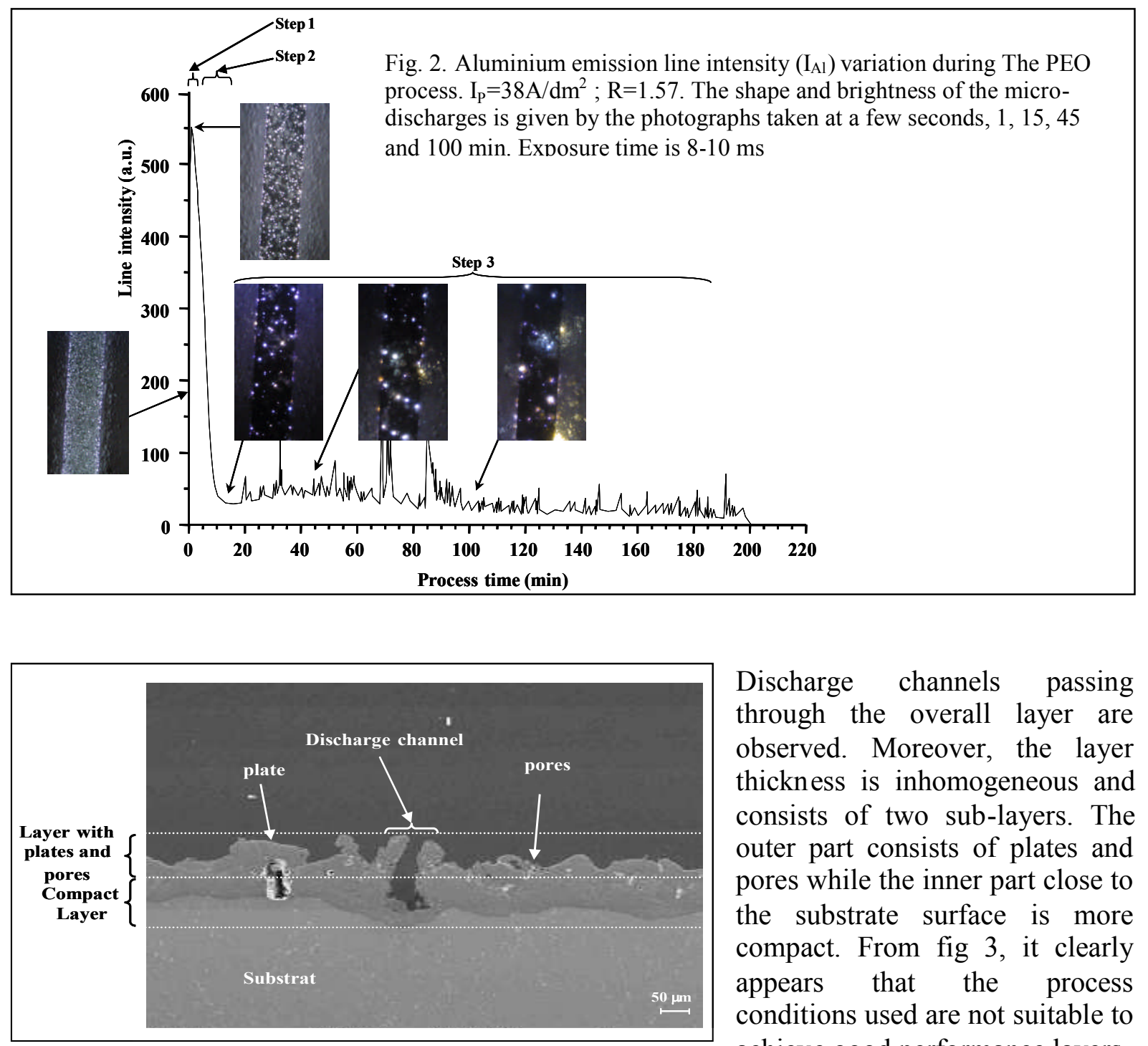

Discharge channels passing through the overall layer are observed. Moreover, the layer thickness is inhomogeneous and consists of two sub-layers. The outer part consists of plates and pores while the inner part close to the substrate surface is more compact. From fig 3, it clearly appears that the process conditions used are not suitable to

Fig. 3. SEM cross section of an oxide layer achieve good performance layers. grown during $140 \mathrm{~min} . \mathrm{I}_{\mathrm{P}}=38 \mathrm{~A} / \mathrm{dm}^{2} ; \mathrm{R}=1.57$.

\subsection{Sample processing} with $R=0.89$

By adjusting the $R$ value, it is possible to modify the behaviour of the process and particularly at long treatment time. The right choice of $R$ value may allow us to define some "smooth" conditions for which no detrimental arcing appears during step 3. This is illustrated in fig. 4 that can be compared with fig. 2 .

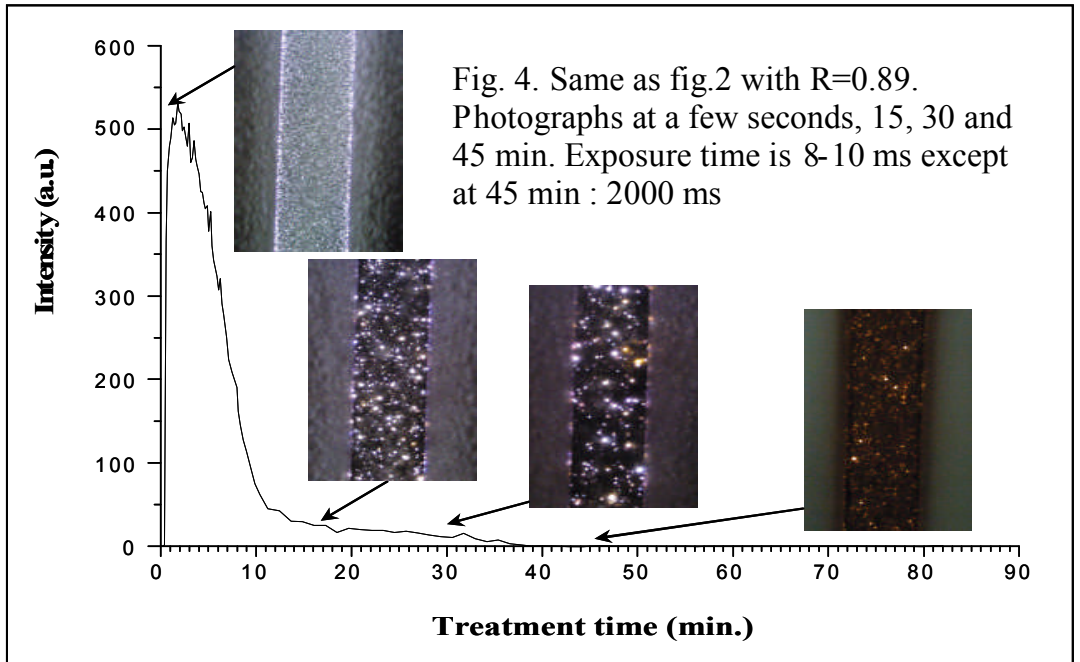


It is worth noting that the major changes occur during step 3. Indeed, the first two steps are rather unchanged with the new process conditions. On the other hand, the strong arcing does not stand anymore and the micro-arcs change to some dark small sparks that can only be seen in the obscurity. This points out a total modification of the process regime that switches from an "arc" regime to a "softer" one which does not exhibit the strong arcs which are detrimental to the oxide layer. Within these particular current conditions and after $60 \mathrm{~min}$. of PEO treatment, the oxide layer thickness becomes more homogenous and the layer-substrate interface is smooth (fig. 5). The oxide layer is still composed of two sub-layers but the plates that formed the top layer in the process with $\mathrm{R}=1.57$ have disappeared giving place to a porous layer.

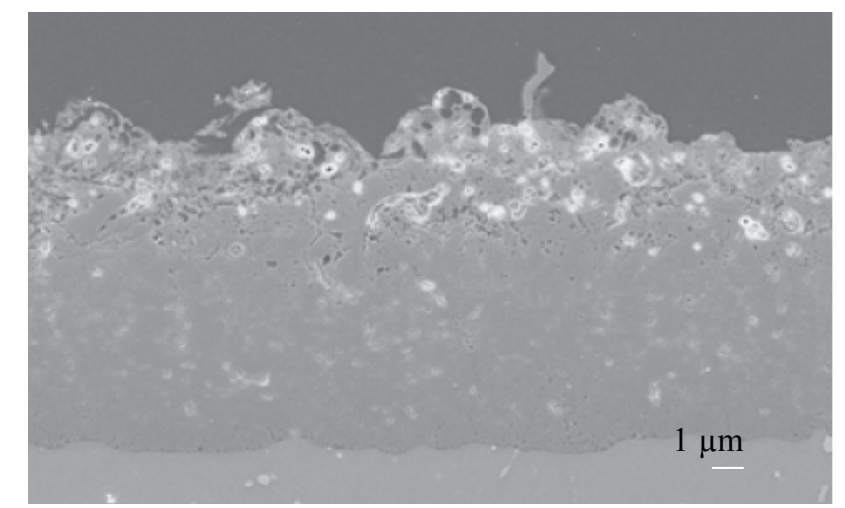

Fig. 5. SEM micrograph cross-section after a $60 \mathrm{~min}$. processing with $\mathrm{R}=0.89$.

\section{Conclusion}

The PEO processing of aluminium alloys has been investigated for different ratio of positive to negative current. From OES discharge investigations and SEM analysis of the processed samples, it appeared that the PEO process behaviour is similar in both conditions during the first steps of the treatment, typically up to treatment time close to $40 \mathrm{~min}$. On the other hand, it has been established that applying a higher negative charge quantity than the positive one to the substrate greatly improves the resulting oxide layers, especially in terms of thickness and homogeneity over the whole surface, strongly reduces the presence of large discharge channels in the final layer.

These results point out the importance of the negative current alternation in the PEO process and the need of using a bipolar current supply with adjustable parameters.

However, it is necessary to refine this study in order to better define the exact current conditions for the establishment of the "softer" regime.

\section{References}

1. A.L. Yerokhin, X. Nie, A. Leyland, A. Matthews, S.J. Dowey, Surf. Coat. Tech. 122 (1999) 73.

2. G. Markov and G. Markova, USSR Patent 526 961, Bulletin of Inventions 32 (1976).

3. P. Kurze, W. Krysmann, H.G. Schneider, Cryst. Res. Technol. 21 (1986) 1603.

4. F. Monfort, A. Berkani, E. Matykina, P. Skeldon, G.E. Thompson, H. Habazaki, K. Shimizu, J. Electrochem. Soc., $152(2005)$ C382.

5. Special issue on "Plasma-assisted electrochemical techniques for treatment of metal surfaces", Surf. Coat. Technol., 199 (2005)

6. R.C. Barik, J.A. Wharton, R.J.K. Wood, K.R. Stokes, R.L. Jones, Surf. Coat. Technol. 199 (2005) 158

7. W. Xue, Z. Deng, Y. Lai and R. Chen, J. Am. Ceram. Soc. 81 (1998) 1365

8. A.L.Yerokhin, L.O.Snizhko, N.L.Gurevina, A.Leyland, A.Pilkington and A.Matthews, J. Phys. D 36 (2003) 2110

9. B.H. Long, H.H. Wu, B.Y. Long, N.D. Wang, X.Y. Lu, Z.S. Jin, Y.Z. Bai, J. Phys. D 38 (2005) 3491

10. J. Beauvir, Patent WO 01/81658 A1 (2001).

11. F.Mécuson, T.Czerwiec, T.Belmonte, L.Dujardin, A.Viola and G.Henrion, Surf. Coat. Technol. 200 (2005) 804.

12. F. Jaspard-Mécuson, T. Czerwiec, G. Henrion, T. Belmonte, L. Dujardin, A. Viola, J. Beauvir, Surf. Coat. Technol. 201 (2007) 8677.

13. A.V. Timoshenko, Yu. V.Magurova, Protection of metals 31 (1995) 474 